\title{
Implementation Local Government Law No. 15 of 2011 On The Implementation Of Hygiene In Village Way Acai Riverbank Mhorock Abepura District Jayapura
}

\author{
Ferry Yan Korwa \\ University Of Cenderawasih
}

\begin{abstract}
Communications Policy Implementation Performance Against Regional Regulation No. 15 Year 2011 on the Implementation of Hygiene it can be concluded as follows: 1) .Variable of data on Communication Policy indicates that communications made in the implementation of Operation Cleanliness in river Acai Mhorock Wai village Abepura District Jayapura City is already effective, the information distribution process (Transmission of Information), Information Clarity and Consistency of Information Effectively work already. This fact is supported by the results of Recapitulation of data on communication policy with effective variable categories obtain a frequency response of $10(43 \%)$ of the 23 respondents who Gave responses. This means that communications made in the implementation the organization of cleanliness has been running. 2) Implementation Performance rule. Rule with Number 15 Year 2011 concerning Cleanliness in river Acai Wai Village Mhorock Abapura Jayapura city district on the Recapitulation say that variable implementation performance said to be high, this situation Proves of the Recapitulation of data on the variable performance with the acquisition Implementation frequency of $12(52 \%)$ with a high response categories indicates that access, coverage and service delivery has been high in the implementation of the program for implementation of hygiene in river Acai Mhorock Wai village Abepura District Jayapura City. 3) .Relate between variables Communication Policy with variable Implementation performance PERDA Number 15 Year 2011 on the Implementation of Hygiene, starting from the results of research conducted it has been known that there is a significant correlation between the variables for Communication Policy $(X)$ with variable performance PERDA No. 15 Implementation in 2011 on the organization of cleanliness in river Acai Mhorock Wai village Abepura District Jayapura City.
\end{abstract}

Keywords: Implementation, performance.

\section{INTRODUCTION}

Pollution that occurred in the city of Jayapura is very alarming, and it is certainly not the only task of Jayapura city government but also need the support of all parties, particularly the citizens of the city of Jayapura in maintaining the cleanliness and environmental sustainability. Conditions around the bay which began contaminated plastic waste such as that found in the coastal region of Cloudy that has long been a concern. By DR. Janviter Manalu, M.si head S2 Program Management of Natural Resources and Environment (PSDAL) of research results predicted in the next 50 years will be half the Gulf Youtefa land if no immediate treatment seriously.

There are four rivers / times which empties into the Gulf Youtefa namely river Acay, Kali Hanyaan, Kali anafre and river Sborhonyi. From the fourth time bigest Acai is a contributor to waste. For along time the flow of is filled with residential areas. This condition is exacerbated 
by land clearing activity in the upstream which ultimately contributed to the Gulf Youtefa material.

Acai River (Acai) lies between Abepura and Kota Raja, flows and empties into the Coastal Water Enggros Coast, Gulf Youtefa. This time is one area of the Watershed (DAS) in the city of Jayapura which has been littered with various rubbish and waste water from urban community activities. There are some big trench potentially contributing household waste water, waste office, workshop, car washes, markets, shops and other domestic waste that could potentially pollute the river water.

The problem in this study can be formulated in the following questions:

1. What level of communication rule No. 15 Year 2011 on the Implementation clean it time Mhorock Acai Village Way?

2. How is the performance of implementation Rule No. 15 Year 2011 on the Implementation Cleanliness in river Acai at Mhorock Way?

3. How is the relationship between communication policy towards the implementation of the performance PERDA No. 15 of 2011 on the organization of cleanliness in river Acai Mhorock Village Way?

\section{Communication Policy \\ Understanding Communication}

Communication is the process of delivering information from the communicator to the communicant. Meanwhile, communication is the process of delivering the policy means the policy information from policy makers (policy makers) to implementing the policy (Widodo, 2011: 97) .According Agustino (2006: 157); "Communication is one-on-one important variables that affect public policy implementation, communication determine the success of the objectives of public policy implementation". Effective implementation will be done, if the decision makers know about what they would do. Opera-known decision-makers can only be obtained through good communication. There are three indicators that can be used in variable success measure communication. Edward III in Agustino (2006: 157-158) suggests these three variables, namely:

1. Transmission. Distribution of good communication will be able to produce a good implementation anyway. Often there are problems in the distribution of communication namely misconception (miscommunication) caused many levels of bureaucracy that must be passed in the communication process, so that what is expected halfway.

2. Clarity. Communications received by the policy implementers (street-level-bureaucrats) must be clear and not confusing or ambiguous / unambiguous.

3. Consistency. Orders were given in the implementation of a communication must be consistent and clear to set or run. If the command is given frequent changes, it can cause confusion for implementers in the field.

Based on the results of the study are summarized in Edward III Winarno (2005: 127) There are some common obstacles that commonly occur in the transmission of communications, namely: "First, there is a conflict between the implementers of the order issued by policy makers. Conflicts of this kind would lead to distortions and obstacles directly in communication policy. Second, the information conveyed through multiple layers of bureaucratic hierarchy. Distortion communication can occur because of the long chain of information that could lead to biased information. Thirdly, the issue of the arrest information is 
also caused by the perceived and the inability of the executive to understand the requirements of a policy".

1. Transmission: before officials can implement a policy he should be aware that a decision has been made and an order for execution has been issued. The transformation of information requires that information is not only communicated to the implementers but also to target groups and other interested parties. It is not always a direct process as it seems. Lots found these decisions are ignored or otherwise, there is often a misunderstanding of the decisions issued. There are several obstacles that arise in transmitting commands first implementation, disagreement between the executive with the instructions issued by the policy makers, the second, the information passed layered bureaucratic hierarchy. As is known bureaucracy has strict structure and tend to be very hierarchical.

2. Clarity: if policies are implemented as desired, then clues executive must not only be accepted by the policy implementers, but also the policy should be clear communication. Often only instructions were passed on to executors vague and did not specify when and how a program is implemented. Obscurity communication message conveyed regarding the implementation of policy leads to an incorrect interpretation may even be contrary to the meaning of the original message. However, the vagueness of communication messages issued by the government policy does not necessarily preclude implementation.

3. Consistency: if it wants to be effective implementation of the policy, then the commands execution must be consistent and clear. Although the commands are communicated to the policy implementers have an element of clarity, but if the order were contrary then the command will not ease the policy implementers carry out their duties properly. On the other hand, the commands implementation inconsistent policies will encourage the executive to take action very loose in interpreting and implementing the policy.

\section{Understanding Policy}

The term policies indicates a series of alternatives that are chosen based on certain principles, while the term expediency signifies a decision that something that was forbidden to know otherwise.

Anderson (1975) Public policy is a policy that is built by department and government officials, where the implications of the policy are:

1. Public policy always has a specific purpose or actions that are goal-oriented.

2. Public policy shows the government's measures.

3. Public policy is what is actually done by the government so it is not what they intended to do.

4. Public policy taken may be positive in the sense that the government's actions regarding everything a particular problem, or is negative in the sense of a government decision not to do something.

5. The government policy at least in a positive sense is based on legislation that is binding and force. 


\section{Stages of Public Policy}

William N. Dunn in (Budi Winarno 2012: 35) explains the stages of public policy sebaga i follows:

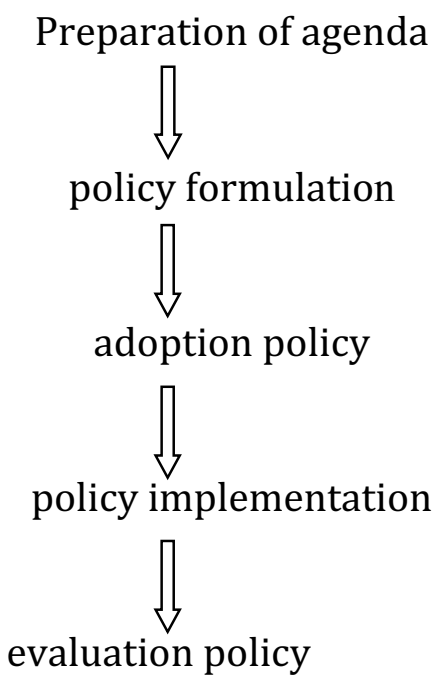

\section{Stage setting the agenda}

Officials put the issue on the public agenda before this issue competed to enter additional policy agenda policymakers

\section{Stages of policy formulation}

The problem that has been entered into the policy agenda was discussed by policy makers. These problems are defined and subsequently look for the best problem solving.

\section{Policy implementation stage}

Policy program decisions that have been taken as an alternative troubleshooter then implemented, which is implemented by administrative agencies and government agencies lower level.

\section{Policy evaluation phase}

Policies that have been implemented will be assessed or evaluated, to see the extent to which policies are made has been able to solve the problem.

\section{Indicators for Communication Policy}

The factors are the most important part of the communication policy in conducting joint activities as follows:

1. The transformation of information (transmission): The information is not only communicated to the implementers but also to the target groups and stakeholders.

2. Clarity of information (clarity): The information is clear and easy to understand in order to avoid misinterpretation of policy implementation.

3. Consistency of Information (consistency): The information submitted must be consistent so as not to cause confusion implementing policies, the target group or related parties.

\section{Performance measurement framework}

In order to determine the level of performance with the implementation, then evaluate the performance (performance measurement) are important. Assessment of the performance is the application of the method used by the researchers to be able to answer the central question 
in the study of the implementation of (i) what the content and purpose of a policy, (ii) what are the stages of what should o to achieve these objectives and (iii) whether after these stages carried out, implemented last run can realize the objectives of the policy or not.

\section{Performance measurement policy implementation}

A policy implemented with the goal of achieving policy goals. Policy goals intended to be achieved through a process called delivery mechanism on the production of policy outcomes (policy outcomes). Comparison between policy outcomes and policy goals is a function of the performance policy so that it can be made the following formula:

\section{Policy performance $=$}

\section{Policy outcomes}

\section{Policy goals}

To measure the performance of policy implementation can use the effects of policy indicators, and policy implications. Policy effect is a consequence rather than policy l output while the policy impact is the impact that emerged after the policy effect. Policy effect can be measured by several indicators as follows:

\section{Access}

Opportunity the target groups for gain equal access to the program or policy without limited by differences in ethnicity, religion, gender, race, social class and others.

\section{Scope}

Related to how big the target group that has been reached by a policy. To measure the target groups have been reached usually used a comparison between the target groups with realization.

\section{Frequency}

Related to how often the target groups obtain the services of a program.

\section{Refraction}

Services related to the targeting accuracy of a program whether it was right on target group or not.

\section{Service delivery (accuracy of service)}

The timelines service related delivery in the implementation of the program. Type of service more beneficial to target groups if given the time they need them.

\section{Accountability}

The policy impact is the goal to be achieved by the policy of the program. This is usually adjusted with the aim of policy, program, or project.

\section{LITERATURE REVIEW}

Communications policy is the process of delivering information from the communicator to the communicant. Meanwhile, communication is the process of delivering the policy means the policy information from policy makers (policy makers) to implementing the policy (Widodo, 2011: 97). 
Performance implementation of the level of achievement of the implementation of performance goals and objectives of a policy, either in the form of policy outputs, as well as the results of the policy.

\section{Definition Operational}

a) Communication policy is process of delivering the policy information from policy makers (policy makers) to implementing the policy in riverbanks Acay village Way Mhorock district Abepura.

b) Performance Implementation picture of the level of achievement of the implementation of performance goals and objectives of a policy, either output policy, as well as the results of policies in riverbanks Acay village Way Mhorock district Abepura.

\section{Performance indicators Implementation}

Access

Opportunity for the target groups gain equal access to the program or policy without limited by differences in ethnicity, religion, gender, race, social class and others.

\section{Coverage}

Related to how big the target group who can by a policy. To measure the target groups have been reached usually used a comparison between the target groups with realization.

\section{Service delivery (accuracy of service)}

Timeliness service related to delivery in the implementation of the program. Type of service more beneficial to target groups if given the time they need them.

\section{RESEARCH METHODS}

The research method is basically a scientific way to get data with a specific purpose and usefulness. Based on these data, there are four key, namely: scientific way, the data, the purpose and usefulness. Related to the type of research conducted that research forms associative then this paper is as follows:

\section{Research sites}

The research will be planned on a time Acai Way Mhorock Abepura district of Jayapura.

\section{Population and Sample}

a) Population is the subject of research (Arikunto 2006: 130). Based on the above, the opinion of the target population in this study is a society that is on the banks of Kali Acai Village Way Mhorock Abepaura Jayapura city district as much as 274 KK (Head of Family).

b) The sample is part of a number of characteristics which is owned by the population. The sample is part of the population who have to follow certain procedures in order to represent the population, with the provision that the sampling could be taken between $10-15 \%$ or $20-25 \%$ (Arikunto 2006: 134). Sample selection is done because of the limitations of time, cost and effort in researching overall population. Sampling was also based on a simple random sampling technique. Told simple random sampling for all citizens in river has an equal chance as a member of a sample of the population was randomly opportunity ta $\mathrm{n}$ pa noticed strata that exist in the population. As for determining the large sample size using formula Taro Yumame authors cited by Rachmat in Riduan (1998: 82) as follows: 


\section{Information:}

$$
\mathrm{n}=\frac{\mathrm{N}}{N \cdot d^{2}+1}
$$

n: number of samples

N: Total Population

d 2: Precision set

The primary data source is data sources directly provide data to data collectors.

To obtain the primary data that I use is:

I. Observation is a technique of data collection by observation. As well as systematically recorded with symptoms related to the problems examined.

II. Interview (interview) is collecting data to ask questions verbally to the respondents to obtain the necessary data.

III. Questionnaire (questionnaire) is a technique of data collection is done by giving a set of questions or a written statement to the respondent to answer.

\section{Secondary data source}

Secondary data sources are the source of the data obtained through library research that is by researching and studying books, scientific papers, journals and other sources other literature related to the issues examined.

\section{Data Processing Techniques}

Once the data is collected, the following activities are to test the hypotheses that have been formulated with regard to whether formulated.

\section{Repairs (editing)}

At this stage check the data have been obtained from the respondents, in order to determine the certainty of data and the relevance of the answers to determine whether the data obtained from the respondents used or not.

\section{Encoding (coding)}

At this stage in the process of checking the data is complete, and then made the clarification answers in categories according to types, namely the provision of a code into the same category.

\section{Preparation of (tabulating)}

After activity data clarification, followed by the drafting of data that have been obtained in the form of tables, then created a summary table, which contains data based on each indicator.

Thus, the data processing techniques in this study is qualitative by using a simple percentage formula according to Anto Power (1991: 71) as follows:

$$
\begin{aligned}
& F \\
& P=X 100 \% \\
& N
\end{aligned}
$$


INFORMATION:

$$
P=\frac{F}{N} \times 100 \%
$$

P: percentage

F: Frequency

N: Number of Respondents

100\%: Constant Value

\section{Data analysis technique}

Data analysis is the process of compaction becomes a value in interpreting the results of the analysis be expected from the conclusion can be drawn that contains the essence of the entire chain of events / research and make recommendations.

Thus the technique of analysis in this study is a qualitative analysis combined with quantitative and simple based on the development problems in the studied population, then minimized by making an analysis of the study sample that has been set

\section{DISCUSSION RESULT}

In this chapter the authors will present data from the research that has dikukan in the field with a division questioner / research instrument to the 23 respondents in the study site. Researchers found the facts that contribute to the process of analysis. In this chapter, the author will make the data or information into the form of simple tables and charts to be easily understood by readers of the order or levels in the presentation of the data by setting the first variable is the communication policy and related indicators comprising the transformation of information, clarity of information and consistency information and implementation of the performance variables in terms of access, coverage and service delivery. Here is a way of presenting data from a study conducted by researchers who have carried out.

\section{Variable Communication Policy}

Communication policy is process of delivering information from the communicator to the communicant. Meanwhile, communication is the process of delivering the policy means the policy information from policy makers (policy makers) to implementing the policy communication is one of the important variables that affect public policy implementation, communication determine the success of the objectives of public policy implementation. 


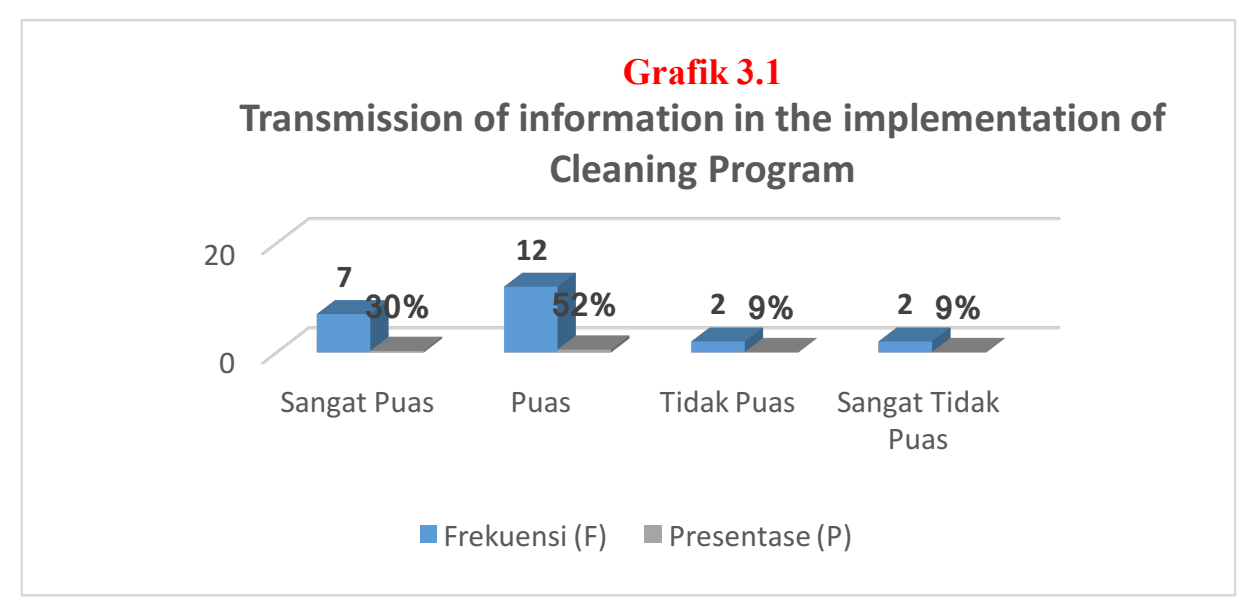

\section{Transformation Indicators Information}

Presentation of the data tables and charts above can be described answers from 23 respondents regarding the transmission of information or the distribution process of communication in the implementation of the Operation Cleanliness known for answers to very satisfied 7 (30\%) of respondents, 12 (52\%) of respondents answered satisfied and answers dissatisfied and very dissatisfied 2 (9\%) of respondents. From these explanations it can be seen that the response categories are satisfied very much the frequency is $12(52 \%)$ of the 23 respondents who gave a response, this means that the process of distributing information by program actors in the implementation of the organization of cleanliness implemented effectively and aces community is very easy in looking for sources of information.

As in conversations with people around the banks of Br Ricco said:

"... Once the notice boards whose contents not to throw garbage at times just a little bit, but now notice boards with billboard display along this road lot and this helps the community here. As well a ban if there were hard for littering especially in times. Say happy because it is not we who live here who read it but everyone who passes definitely read it".

\section{Indicators Clarity Information}

Presentation of the data tables and charts above can be described answers from 23 respondents regarding the clarity of the information on implementation of the Program Operation Cleanliness known to answer very clear $5(22 \%)$ of respondents, 12 (54\%) of respondents answered clearly and the answer is not clear 4 (17\%) and very unclear 2 (9\%) of respondents. From these explanations it can be seen that the response categories obviously very much in frequency that is $12(54 \%)$ of the 23 respondents who responded, starting from Ricco Br response that:

"...... If for me the language used is very simple and everyone can get the point"

This means that the clarity of the information carried by the actors in the implementation of the program Operation Hygiene program has been running effectively so that the community is aware of the intent and purpose than any hygiene programs to be conducted.

\section{Consistency Indicators Information}

The command is given changing it can cause confusion for any executive in the field. To find out how the level of consistency in every communication made the presentation of data in tables and charts above can be described answers from 23 respondents regarding the 
consistency of information on the implementation of the Operation Cleanliness known for answers is consistently $2(9 \%)$ of respondents, 7 ( $30 \%$ ) of respondents answered consistent, inconsistent answers 9 (39\%) and very inconsistent answers 5 (22\%) of respondents.

From these explanations it can be seen that the response categories are satisfied very much the frequency is $12(52 \%)$ of the 23 respondents who gave a response, this means that consistency in communications made by the offender programs in the implementation of the program has not been effective so that the implementation of the program as do not run according to the set time. This means that all the planned work that can be completed quickly, but because of the delay time or not committed by the perpetrator program.

The same thing was said by M. Safri:

"I see that day Sundays and holidays janitor lift garbage often advent afternoons and when it comes to penalties I have not seen or heard there are people who have been fined yet if mo arguably in violation."

That indicators of communication of the implementation of the Operation Hygiene held in river Acai is said to be interconnected with each other where each communication in the implementation of Operation Cleanliness is very necessary.

\section{Implementation performance}

Performance is a success (success) an action, task or operation performed by a person or organization. Performance can thus refer to the output (output), results (outcome) and achievement. If it is associated with a policy can be defined as a picture of the level of achievement of the implementation of performance goals and objectives of a policy, either in the form of policy outputs, as well as the results of the policy.

To determine the performance level of implementation policy number 15 Year 2011 on the Implementation Cleanliness author gives a question concerning indicators of implementation performance in the implementation of the Program Implementation of Hygiene. Indicators used to measure the performance level of implementation the access, coverage, and service delivery.

\section{Access Indicators}

The same is also described with reference to the next diagram, showing the highest percentage on community access indicators are in the category of "always", it can be said that can be said to have been effective.

As in the conversation with Mrs. Irma says:

"...... Used also in were scattered, vat placed beside the road and sometimes to the bad smell, But is now beginning to clean because there are bins provided."

with reference to the diagram in addition, delivery indicator service highest percentage in the category "very good", it can be interpreted that the timeliness and the provision of services in exercising their implementation program has a maximum hygiene.

As the interview given by the mother Ema A. Rumbay, SH.MM (Head of Sub Division of Planning) says that:

"...Every district coordination by a field coordinator (coordinator) and they will control daily cleaning activities and for the provision of public hygiene no collection or 
payment. Also we provision of facilities such as transport trucks that come in every alley, and to trash in we normally do two times a month, funded by the PU. So if PU gives us budget then we will do, and our main task to prepare the means and the janitor in order to keep the environment clean every day. "

\section{Recapitulation Variable Data Communications Policy}

Recapitulation Communication Policies in this chapter can be known indicators used on variable communication policies, namely: Transmission, Clarity, and consistency. These three indicators have a very strong relationship between each other so that we can see in Table 3.4.

Based on table 3.4, it can be seen that the respondents to the indicators of the communication policy of the majority of respondents answered with response categories very effectively obtain a frequency of $3(13 \%)$, response categories effectively obtain a frequency of $10(43 \%)$, response categories do not effectively gain frequency 8 (35\%), and very ineffective obtain frequency $2(9 \%)$.

From the answers above can be seen that the number of response categories effectively obtain a very high frequency of $10(43 \%)$ of the 23 respondents who responded this means that the communication policy pursued in river Acai Mhorock Wai Village has been running effectively.

\section{Variable Data recapitulation Implementation Performance}

Recapitulation of the variable performance of the implementation of this chapter is used to assess the success rate of implementation PERDA Number 15 Year 2011 on the Implementation Cleanliness in river Acai Mhorock Wai village. Summary data on variables implantation performance can be seen in Table 3.8.

Based on Table 3.8 it can be seen that the respondents to the indicators of the performance of the implementation program for implementation of hygiene in river Kali Acai Village Wai Mhorock that some respondents answered by category answer very high-gain frequency of 6 (26\%), the category of response is very high gain frequency 12 (52\%), low-gain frequency response category $3(13 \%)$, and very low response categories obtain frequency $2(9 \%)$.

From the above explanation can be seen that the response categories tall obtain the number of frequencies that is as high as $12(52 \%)$ of the 23 respondents who responded this means that the level of performance of the implementation program for implementation of hygiene in river Acai Village Wai Mhorock is already high.

\section{Relationship Between Communication Policy Implementation Program Implementation With Performance Cleanliness}

From the research that has been done in the field showed that there is a strong relationship or significant between variable communication policy with the performance of the implementation program for implementation of hygiene, which means that if the process of communication policy in the form of socialization program, the installation of billboards on every street, and board rules rule No. 15 of 2011, etc., have been performed by actors in both the program level implementation performance PERDA number 15 Year 2011 on the implementation of Cleanliness will go well so that the level of achievement in realizing the implementation of the policy of a goal will be increased in each of the programs undertaken. 


\section{Clarity Information on the coverage}

Based on the data in table 3.2 indicators clarity of conveying information in communications made by the offender programs in the implementation of the organization of cleanliness in river Acai Village Wai Mhorock has been going well this can be proved by the results of the acquisition on the category of the obvious answer to that is 12 (54\%) of the 23 respondents who gave a response, this means that the process of distributing the communication has been going well so performance implementations in river Acai Village Wai Mhorock well it impacts on indicators of coverage can be proved by the results of placement in table 3.6 with frequency $12(52 \%)$ in the category of good answer, it proves that the implementation performance is very high with the accessibility of public policy implementation programs of cleanliness in river Acai Village Wai Mhorock already well underway as workers junk hauling trash every day, people are already disposing of waste in bins are provided and society already dispose of waste according to the specified time.

\section{Clarity Information on Service Delivery}

Based on the data in table 3.2 indicators clarity of conveying information in communications made by the offender programs in the implementation of the organization of cleanliness in river Acai Village Wai Mhorock has been going well this can be proved by the results of the acquisition on the category of the obvious answer is 12 (54\%) of the 23 respondents who gave a response, this means that the information process has been going well so performance implementations in river Acai Village Wai Mhorock well it impacts on indicators of service delivery evident from the results of placement in table 3.7 with the number of frequency of 11 ( $48 \%$ ) in the category of response is very good, it proves that the implementation performance is very high with the timeliness of services and benefits services to the public policy implementation programs of cleanliness in river Acai Village Wai Mhorock been running well as the provision of facilities such as TPS (Disposal garbage), and garbage trucks and motorcycles.

\section{Consistency relationship with Variable Performance Indicators Implementation Consistency Against Information Access}

Consistency of information in communication is crucial implementation of the program so that it can bring a very good impact on access but in fact the consistency committed by the perpetrator program does not conform to what is expected which can be evidenced from the results of placement in Table 3.3 to the amount of frequency 9 (39\%) of category inconsistent answers and the results of the acquisition rather than indicators of access in table 3.5 to the amount of frequency 13 (56\%) with response categories are always of the 23 respondents who gave this response means that the consistency and timeliness of implementation and sanctions against provisions or rules set in communication performed by actors in the program implementation hygiene program implementation has not gone well so that less give a good impact on access.

\section{Information consistency against Coverage}

Consistency of information in communication is crucial implementation of the program so that it can bring a very good impact on access but in fact the consistency committed by the perpetrator program does not conform to what is expected which can be evidenced from the results of placement in Table 3.3 to the amount of frequency $9(39 \%)$ of category inconsistent answers and the results of the acquisition rather than indicators of coverage in table 3.6 to the amount of frequency 12 (52\%) with response categories either of the 23 respondents who gave this response means that the consistency and timeliness of implementation and sanctions against provisions or rules set in communication performed by actors in the program 
implementation hygiene program implementation has not gone well so that less give a good impact on the coverage.

\section{Consistency Against Information Service Delivery}

Consistency of information in communication is crucial implementation of the program so that it can bring a very good impact on access but in fact the consistency committed by the perpetrator program does not conform to what is expected which can be evidenced from the results of placement in Table 3.3 to the amount of frequency $9(39 \%)$ of category inconsistent answers and the results of the acquisition rather than indicators of service delivery in table 3.7 to the amount of frequency 11 (48\%) with response categories was excellent from 23 respondents who gave this response means that the consistency and timeliness of implementation and sanctions against provisions or rules specified in communications made by the offender in the program implementation hygiene program implementation has not gone well thus giving less significant impact on service delivery.

Where the results of the interview said that the public greatly helped

\section{CONCLUSION}

Implementation Performance Against Number 15 Year 2011 on the Implementation of Hygiene it can be concluded as follows:

1. Obtaining data on the variables of Policy Communications shows that communications made in the implementation of Operation Cleanliness in river Acai Village Wai Mhorock Abepura District Jayapura City is already effective, the process of distributing information (Transmission of Information), Clarity of Information, and Consistency Information has been running effectively, This fact is supported by the results of recapitulation data on variable communication policy with effective response categories obtain a frequency of $10(43 \%)$ of the 23 respondents who gave responses. This means that communications made in the implementation of the organization of cleanliness has been running effectively.

2. Related to the Performance Implementation of Regional Regulation No. 15 Year 2011 concerning Cleanliness in river Acai Village Wai Mhorock District Abapura Jayapura City at the recapitulation say that the variable performance implementation is said to be higher, it proves of the recapitulation of data on the variable-performance implementation of the acquisition frequency of 12 (52\%) with a high response categories indicates that access, coverage and service delivery has been high in the implementation of the program for implementation of hygiene in river Acai Mhorock Wai village Abepura District Jayapura City.

3. The relationship between the variables of Policy Communications with variable performance Implementation Regional Regulation No. 15 Year 2011 on the Implementation of Hygiene, starting from the results of research done, it has been known that there is significant correlation between the variables for Communication Policy (X) with variable Performance Implementation of Regional Regulation No. 15 Year 2011 concerning the implementation of Cleanliness in river Acai Mhorock Wai village Abepura District Jayapura City.

4. In connection with the results of the communication policy pursued in the implementation of the program for implementation of hygiene in river Acai Village Wai

Mhorock which has been running effectively, it was suggested some of the following:

1. To the DKP (Department of Hygiene) Kota Jayapura further increase or TPS (waste disposal) as well as the garbage trucks were used in the implementation of future 
implementation of hygiene so that people no longer throw garbage in piggir times and also the enforcement of legal provisions

2. To Section Cleaning, Transportation and Destruction as well as Field Coordinator is expected to further improve the quality of work and working discipline (especially the discipline of time) in carrying out any work programs that can be run in accordance * with its intended purpose.

3. Embankment to the public in village river Acai Mhorock expected to have more awareness to throw garbage in the trash that had been prepared by a predetermined time.

4. And to all the people in river Acai Mhorock Wai village to keep the means that have been prepared by the government.

\section{BIBLIOGRAPHY}

Abdul Wahab, Solichin 2006 , policy analysis from policy formulation to implementation of the State, Earth Literacy , Jakarta Jayapura City Regional Regulation No. 15, 2011. About Operation Cleanliness

Adi Rianto 2005 , Social and Legal Research Methods (fourth edition), Gramet, Jakarta

Bagong Suyanto, 2005, the Social Research Methods (first edition fourth printing), Kencana, Jakarta

http://mulyono.staff.uns.ac.id/2009/05/28/model-policy-implementation-george-edwad-iii/

Keban.T. Yeremias, 2008. Six Dimensions of Public Administration, Gava Media, Jogyakarta

Nugroho Riant 2009, Public Policy (Edition Revised), PT Alex Media Komputindo , Jakarta

Riduan. 2005. Methods And Thesis , Alfa Beta, Bandung

Saa, Septinus. 2013. Textbook: Public Policy: FISIP UNCEN Jayapura

Said Zainal Abidin, 2002 Public Policy : Revised Edition, foundations Pancur Shiva , Jakarta

Subarsono A. G, 2005, the Public Policy Analysis (concept, theory and applications), Reader S student, Yogyakarta

Sugiyono 2008, Methods of Research Administration, Alpabeta, Bandung 